\title{
BIO V: APLICATIVO PARA O ENSINO DE BOTÂNICA NAS ESCOLAS DO CAMPO
}

\author{
BIO V: APP FOR BOTANICAL TEACHING IN THE SCHOOL OF THE COUNTRYSIDE
}

BIO V: APLICACIÓN PARA LA ENSEÑANZA DE BOTÁNICA EN ESCUELAS CAMPO

\author{
Iluanny da Silva Rocha \\ (iD) 9 \\ Licenciada em Educação do \\ Campo (UFPI) \\ iluanny-rocha@hotmail.com
}

\section{Thales Eduardo Galdino \\ Andrade \\ (iD) 9}

Doutorando em Imunologia Básica

e Aplicada (Faculdade de

Medicina de Ribeirão Preto/USP)

thalesandrade@usp.br

\section{Ágata Laisa Laremberg Alves Cavalcanti (iD) 9}

Doutora em Educação (PPGEd/UFPI)

Professora na Universidade

Federal do Piauí (UFPI)

agatalaysa@ufpi.edu.br

\section{Marcones Ferreira Costa

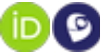

Doutorando em Genética e

Biologia Molecular (PPG-

GBM/UNICAMP)

Professor na Universidade Federal

do Piauí (UFPI)

marconescosta@ufpi.edu.br

\begin{abstract}
Resumo
O presente estudo tem como objetivo compreender a importância do aplicativo Bio V para a melhoria do ensino de botânica nas escolas do campo. Este aplicativo foi elaborado de forma a possibilitar a compreensão dos conceitos botânicos aos alunos campesinos. Trata-se de uma pesquisa qualitativa que descreve o processo de elaboração e avaliação do uso do aplicativo Bio V com dez profissionais da Educação Básica do município de Floriano-Piauí, que atuam em escolas do campo. O Bio V foi avaliado positivamente pela maioria dos participantes, sendo um instrumento facilitador do processo de ensino e aprendizagem. Os dados afirmam a importância do desenvolvimento de ferramentas tecnológicas que aproximem os alunos dos conteúdos de forma dinâmica, objetiva e interativa. Dessa forma, o estudo é de grande relevância para o ensino de botânica, sobremodo, para o fortalecimento da Educação do Campo.

Palavras-chave: Ensino de botânica. Biologia. Tecnologias. Educação do Campo.
\end{abstract}

Recebido em: 22 de janeiro de 2021.

Aprovado em: 21 de julho de 2021.

Como citar esse artigo (ABNT):

ROCHA, Iluanny da Silva et al. Bio V: aplicativo para o ensino de botânica nas escolas do campo. Revista Prática Docente, v. 6, n. 2, e040, 2021.

http://doi.org/10.23926/RPD.2021.v6.n2.e040.id988 


\section{Abstract}

This study aims to understand the importance of the Bio $\mathrm{V}$ application for improving the teaching of botany in rural schools. This application was designed to make it possible for students from rural schools to understand botanical concepts. This is a qualitative research that describes the process of elaboration and evaluation of the use of the Bio V application with ten Basic Education professionals from the city of Floriano-Piauí, working in rural schools. Bio $\mathrm{V}$ was evaluated positively by most participants, being an instrument that facilitates the teaching process and learning. Thus, the study is of great relevance for the teaching of botany, especially, for the strengthening of Rural Education

Keywords: Botany teaching. Biology. Technologies. Rural Education.

\section{Resumen}

Este estudio tiene como objetivo comprender la importancia de la aplicación Bio $\mathrm{V}$ para mejorar la enseñanza de la botánica en las escuelas rurales. La aplicación Bio $\mathrm{V}$ fue diseñada para permitir a los estudiantes de escuelas rurales comprender conceptos botánicos. Se trata de una investigación cualitativa, que describe el proceso de elaboración y evaluación del uso de la aplicación Bio V, con diez profesionales de Educación Básica, del municipio de Floriano-Piauí, que laboran en escuelas rurales. Bio $\mathrm{V}$ fue evaluado positivamente por la mayoría de los participantes, siendo un instrumento que facilita el proceso de enseñanza y aprendizaje. Los datos afirman la importancia de desarrollar herramientas tecnológicas que acerquen a los estudiantes a los contenidos, de forma dinámica, objetiva e interactiva. Por tanto, el estudio es de gran relevancia para la enseñanza de la botánica, especialmente para el fortalecimiento de la educación rural.

Palabras clave: Enseñanza de la botánica. Biología. Tecnologías. Educación rural. 


\section{CONTEXTUALiZAÇÃo INICIAL}

Historicamente, no Brasil, a educação ofertada ao sujeito do campo se desenvolveu por ser veementemente apoiada e defendida por movimentos sociais em busca de políticas públicas que favorecessem a vida rural (SILVA; PASSADOR, 2016). No entanto, as demandas e especificidades desse modelo educacional raramente têm sido objeto de pesquisa no espaço acadêmico, criando um cenário de exclusão, no qual o currículo é essencialmente formado por conotações urbanas, deslocados das necessidades locais e regionais, sendo imperativa a adequação de conteúdos e metodologias (CARDOSO FILHO; DA SILVA, 2017).

A escola do campo é ponto de partida para diversas reflexões sociais; um espaço culturalmente próprio, detentor de tradições, místicas e costumes singulares, o qual tem, por atores principais, o homem e a mulher do campo, sujeitos historicamente construídos a partir de determinadas sínteses sociais, específicas e com dimensões diferenciadas em relação aos grandes centros urbanos (SANTOS, 2017; BICALHO; DE OLIVEIRA, 2018).

Nesse contexto, o ensino de Biologia na Educação do Campo deve preparar o estudante para resolver problemas que evidenciem fundamentos biológicos, como a preservação do ambiente, produtividade agrícola, saúde, responsabilidade social, bioética, dentre outros (SALUSTINO, 2019). Desse modo, o ensino de botânica tem destaque e importância na tentativa de substituir a visão puramente utilitária dos vegetais, movendo esses indivíduos em direção a uma percepção holística em que seres humanos são integrados e interdependentes de outros seres vivos. Para isso, faz-se necessário um ensino de botânica crítico, que seja capaz de transformar a visão e postura da pessoa do campo desde a Educação Básica, onde se desenvolvem os preceitos das interações com o ambiente (SOUZA; GARCIA, 2019).

O ensino de botânica, na Educação Básica, tem sido realizado em paralelo a diversos outros tópicos, os quais nem sempre são relacionáveis, dificultando a transposição didática por parte professores e gerando sensação de sobrecarga de disciplinas e assuntos nos alunos (CLEMÉNT, 2006). Na realidade das escolas rurais, essa sensação é ainda mais presente, visto que os alunos têm a necessidade de conciliar as obrigações escolares com atividades no campo, dificultando uma abordagem mais ampla de conteúdos como a botânica (RIBEIRO, 2013).

Segundo Matos et al. (2015), uma das maiores dificuldades enfrentadas pelos professores ao ensinar botânica é preparar as aulas que aproximem o conteúdo à realidade do aluno. E, entre as ações a serem adotadas para mudar esta situação, destacamos a conscientização dos professores de que o ensino de botânica não precisa se ater apenas às 
informações contidas nos livros didáticos, mas necessita de diferentes recursos didáticos que possam ser utilizados durante as aulas, tornando-as mais atraentes e motivadoras (COPETTI; CANTO-DOROW, 2019).

Dentre os recursos, ressaltamos a presença das Tecnologias Digitais da Informação e Comunicação (TDIC), que sempre caminharam juntas com a educação. Entre os vários recursos tecnológicos para o ensino de botânica destacamos os aplicativos educacionais, uma promissora estratégia de ensino que pode ser aplicada nas escolas do campo (HSIN-CHIH et al., 2013). Ademais, o uso de tecnologia por meio dos aplicativos estimula a participação do aluno de forma dinâmica em sala, potencializando o seu aprendizado e o trabalho em equipe, além de ser uma fonte de conhecimento para estudos fora da escola, o que pode ser realizado pelo preenchimento de questionários e a preparação teórica para exames e avaliações posteriores, sendo mais interativo e dinâmico do que a simples leitura das anotações pessoais ou do livro didático (SILVA, 2018).

Ressaltamos que partimos da compreensão das tecnologias na perspectiva de construção social, segundo a qual o uso dos objetivos educacionais propostos deve ter como foco ser o facilitador da aprendizagem (SANTOS, 2005). Então, é notório que o uso de tecnologias para veicular a informação dentro do contexto escolar e da sala de aula pode contribuir com o processo de ensino e aprendizagem, desde que o mediador deles, que é o professor, saiba fazer com que essas informações se transformem em conhecimento.

Com base no exposto acima, este trabalho tem por objetivo descrever a proposta de uso de um aplicativo criado para abordar conteúdos de botânica em escolas rurais. Denominado por Bio V, foi desenvolvido para auxiliar os discentes do curso de Licenciatura em Educação do Campo/Ciências da Natureza, da Universidade Federal do Piauí, Campus Amílcar Ferreira Sobral (CAFS), em Floriano-Piauí, durante a realização do Estágio Supervisionado, na Educação Básica.

\section{REFERENCIAL TEÓRICO}

A educação nas comunidades rurais vem se modificando com o passar dos anos, porém, ainda sofre com adversidades, sejam elas estruturais ou administrativas organizacionais, o que faz com que a realidade da Educação do Campo seja ignorada, não sendo supridas suas necessidades específicas e então se aceitando a reprodução de um processo de ensino completamente urbano (CARDOSO; ARAÚJO, 2012). Nessa perspectiva, os professores de 
escolas rurais devem transformar essa realidade por meio de metodologias que contextualizem o que está escrito no livro didático com o dia a dia dos alunos.

É importante destacar que a formação do professor para atuar na escola do campo e suas metodologias entraram em destaque nos últimos anos com a preocupação de inserir neste espaço uma educação de qualidade voltada para a realidade das comunidades campesinas (ARROYO, 2007). Contudo, é preciso enfrentar o desafio de uma Educação do Campo contextualizada. Em outras palavras: há necessidade de se trabalhar diferentes estratégias de ensino e modelos didáticos, superando a ideia de que existe uma superioridade do método de ensino da cidade sobre o campo.

Sabemos da grande dificuldade em ministrar conteúdos de Ciências e Biologia na Educação Básica, seja em escolas do campo ou urbanas. A botânica, por exemplo, é considerada uma área desmotivante para a maioria dos estudantes, uma vez que não existe uma aproximação entre conteúdo abordado em sala de aula e a realidade do aluno (BOECHAT; MADAIL, 2019). Em consequência disso, grande parte dos alunos possui uma ideia superficial sobre botânica, sem compreender de fato a real importância das plantas e sua aplicabilidade no dia a dia (COSTA; DUARTE; SILVA, 2019).

Segundo Wandersee; Schussler (2001), o desinteresse surge pela dificuldade das pessoas perceberem a relação das plantas com o ambiente e com a própria espécie humana, fenômeno conhecido de "cegueira botânica". Além dessa questão, o vocabulário específico e complexo atribuído à botânica compromete o processo de aprendizagem.

Para Azevedo (2008), o que torna o ensino de botânica desestimulante entre os alunos é a ausência de recursos didáticos e pedagógicos atrativos. A essas questões somam-se a utilização de práticas de ensino tradicionais, centralizadas no conhecimento conteudista. A botânica apresenta ampla terminologia, o que pode ser cansativo, caso seja adotada uma abordagem puramente teórica em sala de aula.

Sendo assim, é aconselhável que os professores adotem diferentes ferramentas didáticas para melhor visualização e compreensão das estruturas vegetais, como raiz, caule, folha e flor (BOECHAT; MADAIL, 2019). Desse modo, metodologias que estimulem e valorizem o desenvolvimento crítico dos alunos devem ser consideradas. Entre elas, destacamos os recursos tecnológicos, como os aplicativos educacionais (SILVA, 2018).

Dentre os vários recursos tecnológicos disponíveis e presentes na escola e no cotidiano dos alunos, encontramos o smartphone. A partir desses aparelhos diversos, aplicativos 
educacionais podem ser obtidos para atender o interesse do professor e do aluno, aproximando a realidade dos estudantes aos conteúdos abordados nas aulas (BACICH; MORAN, 2018).

No ensino de Ciências e Biologia, é possível encontrar múltiplos exemplos da eficácia de aplicativos educativos para o processo de ensino e aprendizagem (LA LUNA et al., 2015; BATISTA, 2018; SOUZA 2017, MANHÃES, 2019). Em geral, estes trabalhos demonstram que o smartphone pode ser utilizado como recurso facilitador da aprendizagem de um conteúdo de Biologia. Segundo Moura (2010), este novo paradigma educacional produz o mobile learning, a aprendizagem móvel, na qual os dispositivos comunicacionais móveis representam um conjunto de alternativas que podem ser exploradas para o ensino e aprendizagem, sendo um importante modelo a ser considerado nas escolas do campo.

Diante dessa perspectiva, consideramos necessário refletir sobre o impacto dessas tecnologias na sociedade de forma geral e, principalmente, nas escolas do campo. Bierhalz et al. (2019) analisaram a concepção dos alunos de uma escola do campo em relação à tecnologia, bem como verificaram questões relacionadas ao acesso e à sua utilização. Estes autores constataram que o telefone celular é uma das tecnologias mais utilizadas e que a maioria dos discentes possui acesso à internet pelo celular. À vista disso, é possível perceber a colaboração do uso das tecnologias para o fortalecimento da concepção de Educação do Campo.

Diante do cenário atual, é indiscutível a importância da tecnologia digital para o ensino de botânica nas escolas do campo. Acreditamos que a implementação dessas tecnologias fornecerá uma maior interatividade entre os docentes e discentes, tendo em vista que o acesso aos dispositivos móveis produz mudanças na forma de compartilhar conhecimento.

\section{Percurso Metodológico}

O presente estudo tem caráter qualitativo (GIL, 2010), visto que o intuito principal é compreender a utilidade do aplicativo desenvolvido. A amostragem é não probabilística, devido, principalmente, aos poucos profissionais com formação especializada para a Educação do Campo em que foi possível avaliar o aplicativo. Para isso, foi aplicado um questionário semiestruturado com profissionais da Educação Básica, com doze questões abertas (Apêndice).

\subsection{ELABORAÇÃo dO APLICATIVO}

O protótipo de aplicativo contendo informações sobre botânica foi desenvolvido no idioma português brasileiro para o ensino de forma interativa. $\mathrm{O}$ aplicativo foi nomeado de Bio $\mathrm{V}$, remetendo à Biologia Vegetal, a grande área de enfoque das ferramentas do software. Os 
conteúdos abordados estão relacionados à classificação e morfologia dos principais grupos de plantas.

A proposta foi elaborada a partir das orientações que a BNCC do Ensino Médio dispõe acerca do ensino de Ciências da Natureza e suas Tecnologias, com ênfase nas aplicações dos conhecimentos científicos e tecnológicos e em suas implicações éticas, sociais, econômicas e ambientais (BRASIL, 2018). Portanto, ao abordar os conteúdos de botânica, buscamos desenvolver nos discentes habilidades para interpretar as formas de manifestação da vida, ao considerar os diferentes níveis de organização.

O aplicativo foi constituído por três espaços de navegação principais: o quiz temático, o texto de apoio complementar para estudos e as informações sobre a equipe de construção do aplicativo. A interface foi projetada a fim de garantir o ajuste a diversos modelos de dispositivos, sem a utilização de imagens 3D. Optamos por essa estratégia para garantir sucesso do carregamento de dados, visto que buscamos o desenvolvimento de uma ferramenta que pudesse ser utilizada off-line após a instalação no smartphone, e que garantisse o fácil download mesmo em redes com sinais de menor potência, que é a realidade de muitas comunidades rurais (Figura 1).

Ao entrar no aplicativo, o usuário encontra uma tela com os 3 tópicos de navegação apresentados no parágrafo anterior, que levam ao jogo de perguntas e respostas, os textos com informações complementares sobre biologia vegetal e algumas imagens. As questões foram elaboradas de forma a proporcionar a interação alunos e conteúdos, na compreensão dos conceitos referente à morfologia vegetal.

Após a elaboração do aplicativo, foi disponibilizado na Google Play Store para distribuição aos professores participantes da pesquisa (https://play.google.com/store/apps/details?id=co.ufpi.bioapp), a fim de avaliar a relevância e potencial do aplicativo como instrumento facilitador do processo de ensino para os alunos da Educação do Campo. As ilustrações foram feitas à mão livre em papel cartão com lápis número 2 super soft black da Faber Castell e elaboradas com base em imagens presente nos livros didáticos de Biologia. 
Figura 1 - Print screen da tela do aplicativo Bio V
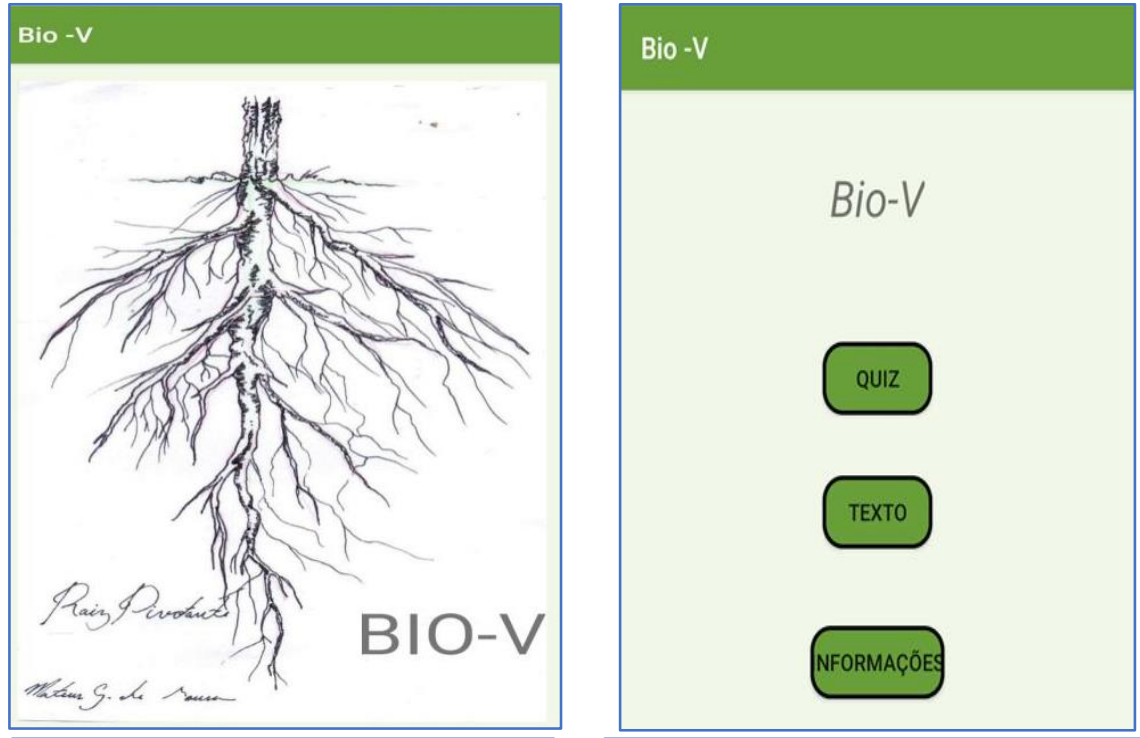

BioApp

BioApp

NA FLOR, A COROLA É O NOME DADO AO:

Você concluiu o quiz

$$
\begin{aligned}
& \text { PEDÚNCULO } \\
& \text { CONJUNTO DE SÉPALAS } \\
& \text { CONJUNTO DE PÉTALAS } \\
& \text { ESTIGMA } \\
& \text { ÓVULO }
\end{aligned}
$$

VOLTAR

PROXIMA

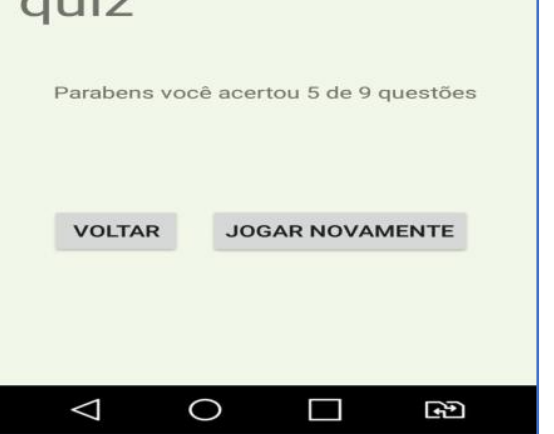

Fonte: Aplicativo Bio V. Disponível em https://play.google.com/store/apps/details?id=co.ufpi.bioapp.

\subsection{Participantes e aValiação}

Para realizar a avaliação do aplicativo Bio $\mathrm{V}$, foram selecionados dez professores de Educação do Campo que ministram a disciplina de Biologia. Todos os participantes atuavam em escolas rurais do município de Floriano-Piauí, Nordeste do Brasil, e tiveram a oportunidade de acesso e utilização do aplicativo em sala de aula. Após os professores utilizarem o aplicativo com seus alunos, receberam um questionário de avaliação da proposta pedagógica a fim de avaliar essa ferramenta para o ensino de botânica. Neste questionário, constavam três seções: 1) perfil do professor da Educação do Campo; 2) perfil do aluno da Educação do Campo; 3) avaliação do aplicativo. Na última seção, o processo de avaliação ocorreu por sistema de notas em escala de 1 a 5 , sendo 1 a menor nota a atribuir e 5 a maior delas. Recebemos a devolutiva 
de todos os professores participantes da pesquisa, conforme apresentamos nos resultados a seguir.

\section{Resultados e Discussão}

Os resultados obtidos a respeito do perfil dos professores indicaram que $20 \%$ dos participantes atuavam na Educação do Campo há, no máximo, um ano, 30\% a mais de um ano e menos de três anos, $20 \%$ a mais de três anos e menos de cinco anos e $30 \%$ a mais de cinco anos.

Quando questionados a respeito das maiores dificuldades ao se lecionar em escolas do campo, destacaram, principalmente, a precariedade em infraestrutura e ausência de recursos didáticos. Ainda citaram as dificuldades do calendário escolar em se adequar às peculiaridades do alunado que necessita de recessos baseados em épocas de colheita, a baixa carga horária em sala de aula, que desencadeia o acúmulo de deficiências em diferentes conteúdos no decorrer dos anos, assim como o cansaço dos alunos por desempenhar "jornada dupla".

Sobre o diferencial dos alunos do campo, os professores apontaram que o desejo desses estudantes por melhores condições de vida desperta o comprometimento com a educação. No entanto, dificilmente conseguem ingressar no Ensino Superior devido não apenas à dificuldade em concorrer por vagas com alunos da zona urbana, mas, principalmente, pela distância geográfica existente entre as universidades e suas comunidades. Outro diferencial seria o uso constante do conhecimento empírico que os permeia, mantendo-os participativos, curiosos, dedicados e compreensivos.

Os participantes da pesquisa ainda opinaram a respeito de metodologias de ensino, sobre as quais $10 \%$ afirmaram que o desenvolvimento de estratégias de ensino diferenciadas não era necessário. Enquanto $90 \%$ afirmaram que metodologias específicas são exigidas, como a construção de modelos didáticos, pois é necessário adequar o ensino à realidade dos alunos para tornar a aula mais atrativa e motivante, além de ajudar na valorização dos indivíduos e do local em que estão inseridos.

O professor precisa ter consciência de que a tecnologia sozinha não transforma o ambiente escolar, mas que origina várias possibilidades de interação com os alunos (SCARPA; CAMPOS, 2018). Não há dúvida de que os recursos didáticos desempenham um importante papel na aprendizagem, conforme destacam Nicola e Paniz (2017) ao ressaltarem a importância do uso de diferentes recursos didáticos para o ensino de Ciências e Biologia. Segundo as 
autoras, vários materiais auxiliam a desenvolver o processo de ensino e aprendizagem, tornando o/a aluno/a mais confiante e capaz de se interessar por novas situações.

Sobre a praticidade de uso do aplicativo, 60\% dos participantes deram nota máxima (5), enquanto $40 \%$ deram nota 4 , demonstrando a autonomia que pode ser conferida aos alunos para estudo solo. Quando questionados a respeito do potencial do Bio V para gerar estímulo nos alunos para que dediquem tempo em casa na própria aprendizagem, $60 \%$ deram nota $5 ; 20 \%$ deram nota 4; $10 \%$ nota 3 e $10 \%$ nota 2 , indicando que é necessário inserir recursos que tornem o aplicativo mais interessante para que, principalmente os adolescentes, tenham iniciativa para usá-lo em casa sem auxílio do professor.

Ao avaliar a relevância dos conceitos de morfologia vegetal existentes no protótipo, $80 \%$ dos participantes atribuíram nota máxima ao conteúdo abordado; $10 \%$ nota 4 e $10 \%$ nota 3. A Educação do Campo se destaca pelo ambiente familiar e amigável que é criado nas interrelações dentro e fora da escola; por esse motivo, questionamos quanto ao potencial do aplicativo Bio V em criar um ambiente positivo entre os usuários, 60\% deram nota 5, 30\% nota 4 e $10 \%$ nota 3 . Acreditamos que houve variação nas notas referentes a esse tópico, por conta da divergência entre professores conservadores e inovadores que possuem diferentes posicionamentos quanto ao uso de smartphones na sala de aula, no qual parte dos educadores acredita que o uso de aparelhos eletrônicos possa distrair os alunos e atrapalhar a aula (REINALDO et al., 2016).

Do mesmo modo, quando questionados sobre promover atitude positiva nos alunos, $60 \%$ deram nota máxima, $20 \%$ deram nota $4,10 \%$ nota 3 e $10 \%$ nota 1 , corroborando com o pensamento exposto anteriormente. Por fim, pedimos uma avaliação quanto ao potencial do aplicativo Bio V em ajudar nas aulas da Educação do Campo, 70\% dos participantes deram nota máxima, $10 \%$ deram nota $4,10 \%$ nota 3 e $10 \%$ nota 1 .

Ao analisar os resultados obtidos, constatamos que a maioria dos professores avaliou positivamente o Bio $\mathrm{V}$, sendo uma importante ferramenta para o processo de ensino e aprendizagem nas aulas de botânica nas escolas do campo, tendo em vista que a utilização dessa tecnologia poderá estimular os alunos, aumentando seu rendimento escolar. Diante desses resultados, notamos que o uso de recursos tecnológicos nas escolas do campo possibilitará a integração direta entre aluno e professor, assim como, será uma nova fonte de estímulo na busca por conhecimento para alunos dentro e fora da escola. 
Salientamos que existem aplicativos educacionais voltados para o ensino de botânica na Educação Básica, como o ClikBotânica, de Souza (2017) e o Botânica na Palma da Mão, de Batista (2017). Entretanto, a particularidade do Bio V em relação aos demais aplicativos é que ele foi pensado e desenvolvido para alunos da Educação do Campo.

O uso das TDIC na educação se destaca pela dinamicidade e interatividade que aproximam conteúdo e aluno. Ao longo do tempo e, considerando o contexto pandêmico, compreendemos que se faz necessário discutir a sua presença e utilização nas escolas do campo. Na cidade de Floriano, as ferramentas tecnológicas têm sido utilizadas na prática pedagógica dos professores, que vêm se adaptando aos novos modelos e às estratégias de para ensinar e aprender (MARTINS; CAVALCANTI; DOURADO, 2020). Entretanto, a tecnologia em si não pode ser vista como a "salvação" do processo de aprendizagem e como a solução para equiparação entre as escolas do "campo" e da "cidade", ela deve ser encarada como uma possibilidade para o desenvolvimento de estratégias de ensino e aprendizagem (BIERHALZ et al., 2019). Além disso, os aplicativos voltados à educação devem ser utilizados como ferramentas didáticas, no qual o professor deve selecionar seus objetivos educacionais para serem alcançados com os recursos disponíveis.

Sob essa perspectiva, percebemos a educação como algo a ser construído, não só pela escola ou pelos recursos tecnológicos, mas também pelas relações sociais, pela interação com o meio a qual o indivíduo pertence. Isso reforça a importância das TDIC, pois, “[...] a evolução levou a tomada de consciência da importância de incorporar as TDIC às práticas pedagógicas e ao contexto da sala de aula" (ALMEIDA, 2003, p, 116). E, se usadas e incorporadas de forma pedagógica no contexto escolar, o professor pode usufruir dos recursos tecnológicos, para uma melhor desenvoltura das suas aulas e, ao mesmo tempo, inovar-se como professor pesquisador, construtivista de modo a reinventar seus métodos e formas de mediar o conhecimento.

\section{CONSIDERAÇões Finais}

$\mathrm{O}$ aplicativo educacional Bio V constitui-se numa ferramenta tecnológica que possibilita a aproximação dos alunos com os conteúdos de forma dinâmica, objetiva e interativa. Destacamos que sua aceitação por parte dos professores participantes da pesquisa contribuirá de forma significativa com as atividades didático-pedagógicas. Além disso, a utilização do Bio $\mathrm{V}$ de forma off-line visa possibilitar o acesso à ferramenta, principalmente, aos alunos de comunidades com dificuldades de acesso a internet. 
A possibilidade de atualização do aplicativo educacional Bio $\mathrm{V}$ deixa espaço para ampliação dessa ferramenta quanto aos conteúdos a serem trabalhados, bem como outras atividades que podem ser inseridas no aplicativo, adequando ao contexto educacional da comunidade, na qual a escola do campo está inserida. Por fim, compreendemos que a proposta que apresentamos, possibilita aos professores de Biologia, inserir na sua prática pedagógica, recursos didáticos para o ensino de botânica, ao tempo que insere as tecnologias no cotidiano da Educação do Campo.

\section{REFERÊNCIAS}

ALMEIDA, Maria Elizabeth Bianconcini de. Educação a distância na internet: abordagens e contribuições dos ambientes digitais de aprendizagem. Educação e Pesquisa, São Paulo, v.29, n.2, p. 327-340, jul./dez. 2003.

ARROYO, Miguel Gonzalez. Políticas de formação de educadores (as) do campo. Cadernos Cedes, v. 27, n. 72, p. 157-176, 2007. Disponível em:

https://www.scielo.br/scielo.php?pid=S0101-32622007000200004\&script=sci_arttext .

Acesso em: 03 set. 2020.

AZEVEDO, Rosa Oliveira Martins. Ensino de ciências e formação de professores: diagnóstico, análise e proposta. 2008. 163 f. Dissertação (Mestrado em Educação e Ensino de Ciências na Amazônia). Universidade do Estado do Amazonas - UEA, 2008.

BACICH, Lilian; MORAN, José. Metodologias ativas para uma educação inovadora: uma abordagem teórico-prática. Penso Editora, 2018.

BATISTA, Thiago da Silva. Recurso de apoio didático para o Ensino de Botânica: aplicativo para o trabalho com Ecologia vegetal no Ensino Médio. 2018. 37f. Trabalho de Conclusão de Curso (Licenciatura em Ciências Biológicas) - Universidade Federal de Pernambuco, Vitória de Santo Antão, 2018. Disponível em:

https://repositorio.ufpe.br/bitstream/123456789/22855/1/BATISTA\%2c\%20Thiago\%20da\%2 0Silva.pdf. Acesso em: 03 set. 2020.

BRASIL. Ministério da Educação. Base Nacional Comum Curricular (BNCC). Educação é a Base. Brasília, CONSED/UNDIME, 2018.

BICALHO, Ramofly; DE OLIVEIRA, Lia Maria Teixeira. Políticas públicas em educação do campo. Rtps-Revista Trabalho, Política E Sociedade, v. 3, n. 4, p. 267-290, 2018.

Disponível em: <http://costalima.ufrrj.br/index.php/RTPS/article/view/297. Acesso em: 04/09/2020.

BIERHALZ, Crisna Daniela Krause; DA FONSECA, Eril Medeiros; DE VARGAS OLIVA, Izalina. Concepções dos estudantes de uma escola do campo sobre tecnologia. Revista Brasileira de Educação do Campo, v. 4, p. e3297-e3297, 2019. Disponível em: https://sistemas.uft.edu.br/periodicos/index.php/campo/article/view/3297/14652. Acesso em: 06 set. 2020. 
BOECHAT, Lorena Temponi; MADAIL, Rafael Hansen. O uso do Qr Code como recurso pedagógico no ensino de botânica morfológica. Revista Eletrônica Sala de Aula em Foco, v. 8, n. 1, p. 50-57, 2019. Disponível em: https://ojs.ifes.edu.br/index.php/saladeaula/article/view/517. Acesso: 04 set. 2020.

CARDOSO FILHO, Ilário Dias; DA SILVA, Cícero. Reflexões sobre a educação do campo. Revista de Educação Popular, v. 16, n. 3, p. 67-83, 2017. Disponível em: http://www.seer.ufu.br/index.php/reveducpop/article/view/38835. Acesso em: 02 set. 2020.

CARDOSO, Lívia de Rezende; ARAÚJO, Maria Inez de Oliveira. Currículo de ciências: professores e escolas do campo. Ensaio Pesquisa em Educação em Ciências (Belo Horizonte), v. 14, n. 2, p. 121-135, 2012. Disponível em:

https://www.scielo.br/scielo.php?pid=S1983-21172012000200121\&script=sci_arttext. Acesso em: 05 jul. 2020.

CLÉMENT, P. Didactic Transposition and KVP Model: conceptions as interactions between scientific knowledge, values and social practices. ESERA Summer School, Universidade do Minho, 9-18, 2006.

COPETTI, Camila; CANTO-DOROW, Thaís. Botany Teaching: An Overview of Academic Research in Brazil from 2002 to 2017. Acta Scientiae. 21. 155-169, 2019.

COSTA, Emanuelle Almeida; DUARTE, Rafaela Andressa Fonseca; SILVA GAMA, José Aparecido. A gamificação da Botânica: uma estratégia para a cura da "cegueira botânica. Revista Insignare Scientia-RIS, v. 2, n. 4, p. 79-99, 2019. Disponível em: https://periodicos.uffs.edu.br/index.php/RIS/article/view/10981/7320 Acesso em: 14 jun. 2021.

GIL, Antonio Carlos. Como elaborar projetos de pesquisa. 5. ed. São Paulo: Atlas, 2010.

HSIN-CHIH, Lai et al. The implementation of mobile learning in outdoor education: Application of QR codes. British Journal of Educational Technology, v. 44, n. 2, p. E57E62, 2013.

LA LUNA, Alexandre et al. O aplicativo MyFitnessPal como recurso promotor da aprendizagem de biologia. Revista Interdisciplinar de Tecnologias e Educação, v. 1, n. 1, p. 259-262, 2015. Disponível em:http://rinte.ifsp.edu.br/index.php/RInTE/article/view/00020007. Acesso em: 05 set.. 2020.

MANHÃES, Marcelle de Oliveira; BATISTA, Silvia Cristina Freitas; DE SOUZA MARCELINO, Valéria. Aplicativos para o ensino de anatomia humana: uma discussão sobre a seleção destes recursos. Revista Cadernos de Educação Básica, v. 4, n. 3, p. 12-33, 2019. Disponível em: http://cp2.gov.br/ojs/index.php/cadernos/article/view/2422/1623. Acesso em: 01 set. 2020.

MARTINS, Andreia; CAVALCANTI, Ágata Laisa Laremberg Alves; DOURADO, Anne Caroline Soares. Educar em tempos de incertezas: a implementação do ensino remoto na rede municipal de Floriano-Piauí. Dialogia, São Paulo, n. 36, p.73-85, set./dez. 2020. Disponível em: https://doi.org/10.5585/dialogia.n36.18619. Acesso em: 04 jan. 2021. 
MATOS, Gilda Maria Amarante et al. Recursos didáticos para o ensino de botânica: uma avaliação das produções de estudantes em universidade sergipana. Holos, v. 5, p. 213-230, 2015. Disponível em: https://www.redalyc.org/pdf/4815/481547288019.pdf. Acesso em: 02 set. 2020.

NICOLA, Jéssica Anese; PANIZ, Catiane Mazocco. A importância da utilização de diferentes recursos didáticos no Ensino de Ciências e Biologia. InFor, v. 2, n. 1, p. 355-381, 2017. Disponível em: https://ojs.ead.unesp.br/index.php/nead/article/view/infor2120167. Acesso em: 03 set. 2020.

REINALDO, Francisco, et al. Impasse aos desafios do uso de smartphones em sala de aula: investigação por grupos focais. RISTI [Revista Iberica de Sistemas e Tecnologias de Informacao], n. 19, p. 77, 2016.

RIBEIRO, Marlene. Desafios postos à educação do campo. Revista HISTEDBR On-line. v. 13. n. 123, 2013.

SALUSTINO, Leandro Mendes. O processo de ensino e aprendizagem de Biologia em consonância com a educação do campo, sob a perspectiva da sustentabilidade. Revista Brasileira de Gestao Ambiental e Sustentabilidade, v. 6, n. 14, p. 787-802, 2019. Disponível em: http://revista.ecogestaobrasil.net/v6n14/v06n14a12a.html. Acesso em:01 set. 2020.

SANTOS, Ramofly Bicalho. História da educação do campo no Brasil: o protagonismo dos movimentos sociais. Revista Teias, v. 18, n. 51, p. 210-224, 2017. Disponível em: https://www.e-publicacoes.uerj.br/index.php/revistateias/article/view/24758 . Acesso em: 02 set. 2020.

SANTOS, Iracy de Sousa. As novas tecnologias na educação e seus reflexos na escola e no mundo do trabalho. JORNADA INTERNACIONAL DE POLÍTICAS PÚBLICAS, 2, 2005. Anais [...], Programa de Pós-Graduação em Políticas Públicas, UFMA, 2005. Disponível em: http://www.joinpp.ufma.br/jornadas/joinppll1/html/Trabalhos2 . Acesso em: 10 jun. 2021.

SCARPA, Daniela Lopes; CAMPOS, Natália Ferreira. Potencialidades do ensino de Biologia por Investigação. Estudos Avançados, v. 32, n. 94, p. 25-41, 2018. Disponível em: https://www.scielo.br/scielo.php?pid=S0103-40142018000300025\&script=sci_arttext. Acesso em: 05 set. 2020.

SILVA, Alexsandro Bezerra da. Aplicativos educacionais: recursos pedagógicos para o ensino de botânica no ensino médio. 2018. 45f. Trabalho de Conclusão de Curso (Licenciatura em Ciências Biológicas)- Universidade Federal de Pernambuco, Vitória de Santo Antão, 2018. Disponível em: https://attena.ufpe.br/handle/123456789/28926. Acesso em: 05 set. 2020.

SILVA, Giuliano; PASSADOR, João. Educação do campo: Aproximações conceituais e evolução histórica no Brasil. Education Policy Analysis Archives. v. 24, n. 78, 2016. Disponível em: https://core.ac.uk/download/pdf/267852827.pdf. Acesso em: 03 set. 2020. 
SOUZA, Cássia Luã Pires; GARCIA, Rosane Nunes. Uma análise do conteúdo de Botânica sob o enfoque Ciência-Tecnologia-Sociedade (CTS) em livros didáticos de Biologia do Ensino Médio. Ciência \& Educação. v. 25, n. 1, p. 111-130, 2019.

SOUZA, Gerlayne Teixeira. Desenvolvimento de aplicativo educacional: proposta pedagógica para o ensino de Botânica com foco em morfologia vegetal. 2017. Trabalho de Conclusão de Curso (Licenciatura em Ciências Biológicas) - Universidade Federal de Pernambuco, Vitória de Santo Antão, 2017. Disponível em:

https://attena.ufpe.br/handle/123456789/22243. Acesso em: 05 set. 2020.

WANDERSEE, James; SCHUSSLER, Elisabeth . Toward a theory of plant blindness. Plant Science Bulletin, v. 47, n. 1, pág. 2-9, 2001. 


\section{APÊNDICE - Questionário: O USO do APLICATIVo "Bio V" na EduCAÇão do CAMPo}

O aplicativo Bio V é um protótipo que tem como principal meta ensinar a classificação e morfologia das plantas de forma interativa, para isso, além do quiz interativo, contém informações sobre o conteúdo. Essas informações terão a função de auxiliar no aprendizado dentro e fora da sala de aula. Assim, o Bio V é um aplicativo voltado para o ensino médio visando a facilitação do aprendizado da morfologia vegetal. Disponível para download (https://play.google.com/store/apps/details?id=co.ufpi.bioapp).

\section{Perguntas}

1. Há quanto tempo você é professor da Educação do Campo?

2. Qual o diferencial do aluno da Educação do Campo em comparação a outros estudantes?

3. Quais as principais dificuldades em se lecionar na Educação do Campo?

4. É necessário o desenvolvimento de estratégias diferenciadas de ensino para alunos da Educação do Campo? Justifique.

5. Você teve acesso ao aplicativo Bio V?

( ) $\operatorname{Sim}$

( ) Não

6. Em uma escala de 1 a 5, quanto o aplicativo Bio V é de fácil uso?

7. Em uma escala de 1 a 5, quanto o aplicativo Bio V introduz conceitos importantes?

8. Em uma escala de 1 a 5, quanto o aplicativo Bio $\mathrm{V}$ tem potencial de deixar os alunos terem iniciativa e autoconfiança para investirem tempo no próprio aprendizado?

9. Em uma escala de 1 a 5, avalie. O aplicativo Bio $\mathrm{V}$ sendo utilizado em aulas poderia criar um ambiente positivo em sala?

10. Em uma escala de 1 a 5 , quanto o uso do aplicativo Bio $\mathrm{V}$ poderia promover uma atitude positiva nos alunos?

11. Com base em tudo que foi respondido, o quanto o aplicativo Bio $\mathrm{V}$ tem potencial para ajudar em aulas na Educação do Campo? 